Article

\title{
Effect of Stress-Strength Ratio on Creep Property of Sodium Silicate-Based Alkali-Activated Slag Concrete
}

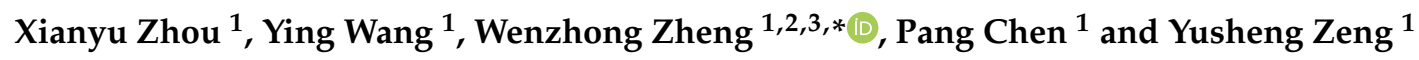 \\ 1 School of Civil Engineering, Harbin Institute of Technology, Harbin 150090, China \\ 2 Key Lab of Structures Dynamic Behavior and Control of the Ministry of Education, Harbin Institute of \\ Technology, Harbin 150090, China \\ 3 Key Lab Smart Prevention and Mitigation of Civil Engineering Disasters of the Ministry of Industry and \\ Information Technology, Harbin Institute of Technology, Harbin 150090, China \\ * Correspondence: zhengwenzhonghit@163.com; Tel.: +86-176-2401-5296
}

Received: 15 July 2019; Accepted: 19 August 2019; Published: 4 September 2019

\begin{abstract}
Alkali-activated materials have attracted increasing interest owing to their excellent properties and environmental protection. However, there have been few studies on their creep properties. The aim of this article is to investigate the effect of the stress-strength ratio on the creep property of sodium silicate-based alkali-activated slag (AAS) concrete. For this reason, five groups of AAS concrete with different stress-strength ratios $(0.15,0.3,0.45,0.6$, and 0.75$)$ were tested. The results indicate that the creep of AAS concrete has a convergent nonlinear stage and a non-convergent stage but not an obvious linear stage. The AAS concrete basically has a consistent creep coefficient and diverse specific creep under a stress-strength ratio of 0.15-0.6. The elasticity modulus of AAS is much smaller than that of ordinary Portland cement (OPC) concrete, which is the reason for the greater creep compared to that in OPC concrete, and the inaccuracy of the model prediction. By applying the actual elastic modulus, the models can predict the specific creep and stress-dependent strain of AAS concrete with a 0.3 stress-strength ratio, except for the B3 model. The secant modulus of AAS concrete decreases linearly with an increase in the stress-strength ratio. Finally, we propose an improved creep model for AAS concrete with a wide stress-strength ratio based on the GL2000 model.
\end{abstract}

Keywords: alkali activated; slag; creep; stress-strength ratio; creep model

\section{Introduction}

With the development of the iron industry, the utilization of its by-product, namely, ground granulated blast furnace slag (GGBFS), has been a problem that needs to be addressed. China, for example, produces over 2.4 million tonnes of such slag per year, the common use of which is as an admixture in Portland cement. However, only $20-30 \%$ of slag can be used effectively [1]. At the same time, Portland cement used in the construction industry consumes large amounts of energy [2] and releases a large amount of $\mathrm{CO}_{2}$ in its production process [3], contributing to global warming. Given that the world is facing energy shortages and serious environmental problems, the use of alkali-activated slag (AAS) as a cementitious binder and an alternative to Portland cement in certain areas may be advantageous. In recent decades, alkali-activated materials have been applied in increasing numbers of practical engineering projects around the world $[4,5]$. Compared to Portland cement, AAS has obvious advantages in its resistance to a chemical attack [6,7] and frost $[8,9]$.

Creep is an important long-term characteristic of concrete, particularly in large-scale structures in which its presence may intensify the occurrence of cracks and deformations. In turn, such conditions deteriorate the resistance to a chemical attack and frost. AAS materials have a high early strength $[10,11]$, 
which may make them suitable for application in pre-stressed engineering. Prior to such application, the procedure of calculating the stress loss is bounded with the creep property [12]. However, compared with concrete made of ordinary Portland cement (OPC), only a few studies on the creep occurring in alkali-activated slag (AAS) concrete have been conducted.

In 1999, Collins and Sanjayan [13] studied the creep in AAS for a period of 112 days, which to the best of the authors' knowledge was the first experiment on AAS creep. They found that AAS concrete has higher creep and a lower elastic modulus than OPC concrete. Nevertheless, only one stress-strength ratio (0.4) for each sample was applied and the creep test time was short. In general, creep should be tested for a period of approximately 200-300 days [14,15] and even up to 1000 days [16]. Ma and Dehn [17] investigated the creep in AAS concrete with two different stress-strength ratios ( 0.35 and 0.5$)$ under different conditions of relative humidity (65\% and sealed) for approximately 180 days. More laudably, they compared the test results with the creep model of CEB-FIP 2010 [18], and found that the experimentally determined creep coefficient of AAS concrete is higher than predicted. Unfortunately, they did not compare the test value with more models or discuss the effects of the stress-strength ratio.

To the best of the authors' knowledge, there have been no more studies on the creep property of AAS concrete. The stress-strength ratio is one of the most important parameters of creep strain. How does the stress-strength ratio affect the creep of AAS concrete, and is it similar with OPC concrete? Several mature code models have already been developed to calculate the creep strain of OPC concrete, and whether they are suitable for AAS concrete should be determined. If not, the ways in which they can be adjusted for AAS concrete should be studied. Such gaps in knowledge have blocked the further practical applications of AAS concrete. Thus, the creep property of AAS concrete requires further study.

Based on the facts above, this study focuses on the creep of AAS concrete under a stress-strength ratio of $0.15-0.75$. Five groups of AAS concrete with different stress-strength ratios $(0.15,0.3,0.45,0.6$, and 0.75 ) were tested. After the tests, we analyzed the results from three perspectives (stress-dependent strain, specific creep, and creep coefficient). We then compared the curves with the current models (ACI 209R-92 [19], B3 [20], CEB-FIP 2010 [18], and GL2000 [21]) and discussed the applicability of such models. Finally, we proposed an improved creep model for AAS concrete with a wide range of stress-strength ratios based on the current model and the test results.

\section{Experiment Procedures}

\subsection{Materials}

The blast furnace slag was supplied by Harbin Sanfa, a new energy-saving building material company in Harbin, China. The composition of the slag is shown in Table 1. The specific surface and specific gravity of the slag were $421 \mathrm{~m}^{2} / \mathrm{kg}$ and 2.9 , respectively.

The activators were prepared by combining sodium hydroxide pellets (Dalu Chemical Reagent Factory, Tianjin, China, $96 \%$ purity $)$ and a commercial liquid sodium silicate $\left(\mathrm{SiO}_{2} / \mathrm{Na}_{2} \mathrm{O}\right.$ ratio $=1.7$, water content of $56 \%$ ).

The water used in these tests was tap water from Harbin. The fine aggregate consists of natural river sand with a maximum size of $2.5 \mathrm{~mm}$, a fineness modulus of 2.55 and $24 \mathrm{~h}$ of water absorption to $0.6 \%$. Finally, the coarse aggregate consists of a maximum of $10 \mathrm{~mm}$ of macadam with $24 \mathrm{~h}$ of water absorption to $1.2 \%$.

Table 1. Chemical composition of slag (\%).

\begin{tabular}{cccccccccc}
\hline Oxide & $\mathrm{CaO}$ & $\mathrm{SiO}_{2}$ & $\mathrm{Al}_{2} \mathrm{O}_{3}$ & $\mathbf{M g O}$ & $\mathrm{Fe}_{2} \mathrm{O}_{3}$ & $\mathrm{Na}_{2} \mathbf{O}$ & $\mathrm{K}_{2} \mathrm{O}$ & $\mathrm{SO}_{3}$ & Others \\
\hline Percentage & 42.27 & 32.84 & 13.61 & 6.83 & 0.66 & 0.38 & 0.28 & 2.21 & 0.92 \\
\hline
\end{tabular}




\subsection{Mixture}

Only one mixture was designed and tested in this study. The w/c ratio was 0.5 , the $M_{\mathrm{S}}\left(\mathrm{SiO}_{2} / \mathrm{Na}_{2} \mathrm{O}\right.$ ratio) was 1.2 , the sodium silicate dosage was $15 \%$ (by slag mass), the slag-to-fine-aggregate ratio was 0.5 , and the fine-aggregate-to-coarse aggregate ratio was 0.5 . The mixture proportions are listed in Table 2. The $\mathrm{H}_{2} \mathrm{O}$ in Table 2 was additional water. Thus, the $\mathrm{H}_{2} \mathrm{O}$ came from commercial liquid sodium silicate, and $\mathrm{NaOH}$ was not included in the $\mathrm{H}_{2} \mathrm{O}$ listed in Table 2.

The water derived from $\mathrm{NaOH} 2 \mathrm{NaOH} \rightarrow \mathrm{Na}_{2} \mathrm{O}+\mathrm{H}_{2} \mathrm{O}$.

Table 2. Mixture proportions used in this study.

\begin{tabular}{cccccc}
\hline Slag $(\mathbf{g})$ & Sodium Silicate $(\mathbf{g})$ & $\mathbf{N a O H}(\mathbf{g})$ & $\mathbf{H}_{\mathbf{2}} \mathbf{O}(\mathbf{g})$ & Fine Aggregate $(\mathrm{g})$ & Coarse Aggregate $(\mathbf{g})$ \\
\hline 1000 & 263.72 & 43.82 & 342.46 & 2000 & 4000 \\
\hline
\end{tabular}

The activator (including liquid sodium silicate, $\mathrm{NaOH}$, and $\mathrm{H}_{2} \mathrm{O}$ ) was prepared in advance in plastic buckets and cooled to ambient temperature. During the cooling period, the activator was covered with caps to prevent water evaporation. The slag was blended with an aggregate by the concrete manufacturer for $1 \mathrm{~min}$ and then added to the activator for another $2 \mathrm{~min}$ of blending. After the mixture was poured out, it was loaded into test moulds and vibrated for $30 \mathrm{~s}$ using a shaker table. The specimens were covered with plastic films in the moulds for three days before demoulding. Figure 1 shows some photographs of the manufacturing operation of the AAS concrete.

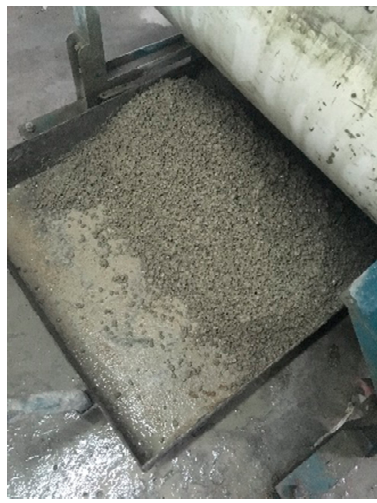

(a)

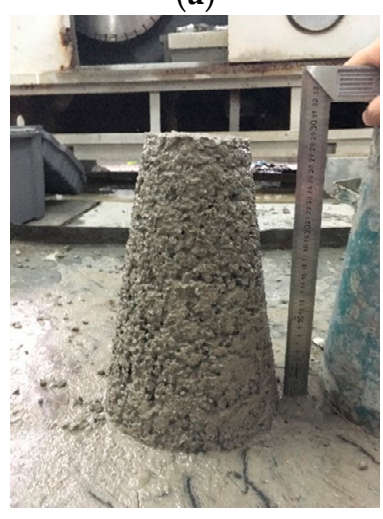

(d)

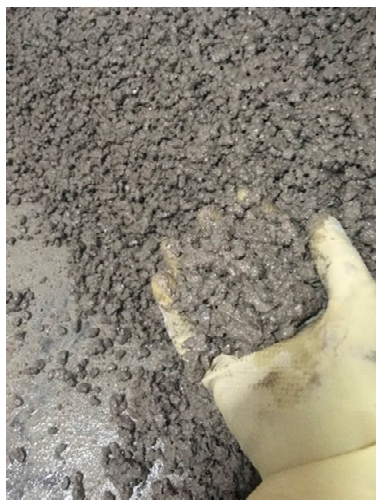

(b)

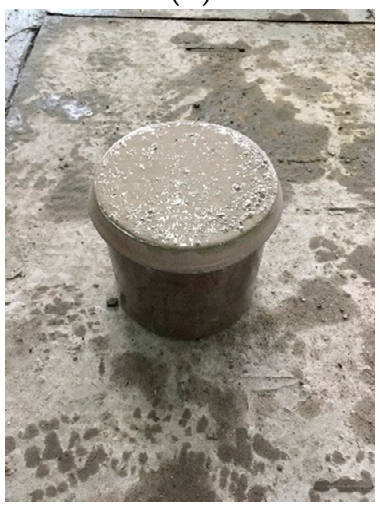

(e)

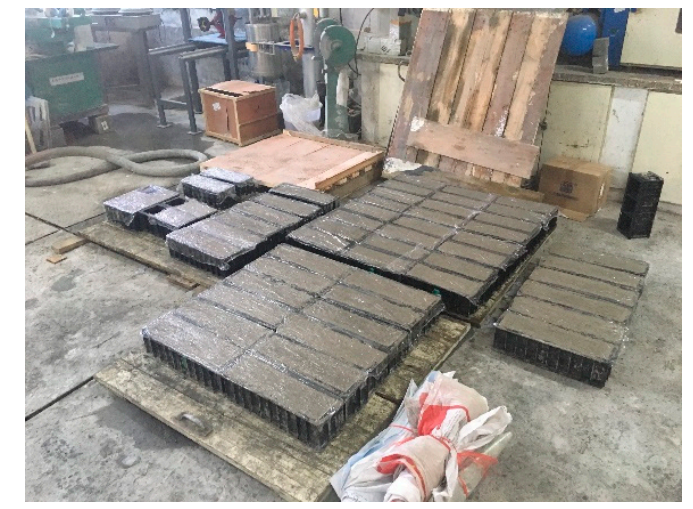

(c)

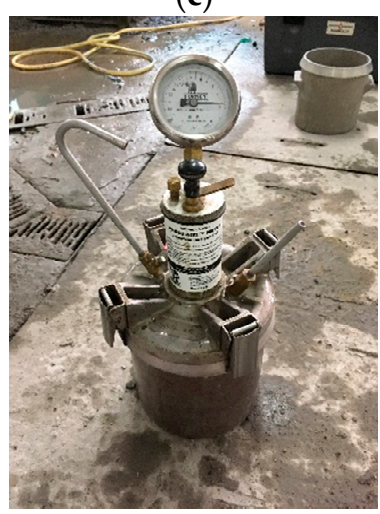

(f)

Figure 1. Manufacturing operation of alkali-activated slag (AAS) concrete: (a) mixture of AAS concrete; (b) state of the mixture; (c) casting of AAS concrete; (d) slump test of the ASS concrete; (e) AAS concrete after vibration; (f) air content test of AAS concrete.

\subsection{Experiment Tests}

The slump and air content of the fresh AAS mixture were tested as shown in Figure 1d-f. 
After the specimens were demoulded, they were cured in a chamber at a temperature of $20 \pm 2{ }^{\circ} \mathrm{C}$ and relative humidity of $60 \pm 3 \%$ during the tests. The tests included the compressive strength, elastic modulus, shrinkage, and creep. The accuracy of the dial gauges used in shrinkage and creep tests was $0.001 \mathrm{~mm}$.

As Figure 2 shows, the prismatic specimens with dimensions of $100 \times 100 \times 300 \mathrm{~mm}$ were prepared for compressive strength and elastic modulus measurements. Two strain gauges were attached to the opposite sides of each specimen to check the bias during the compressive test. Two dial gauges were also attached to the opposite sides of each specimen to test whether the elastic modulus follows the GB/T 50081-2002 code [22]. The two tests were conducted over a 28-day period $\left(\mathrm{t}_{0}\right)$.

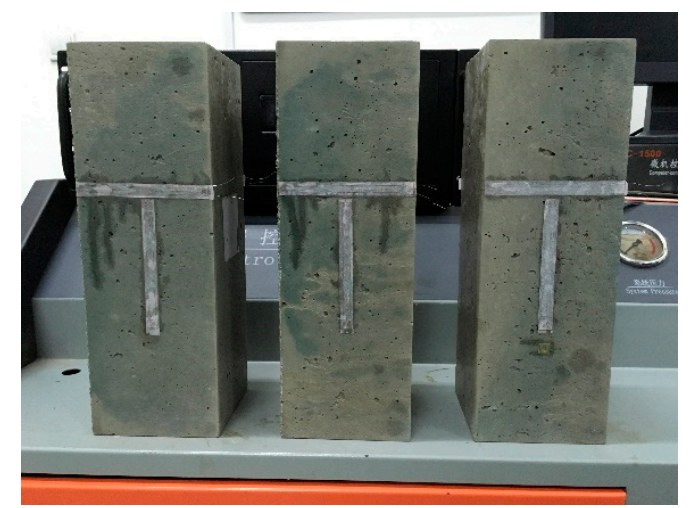

(a)

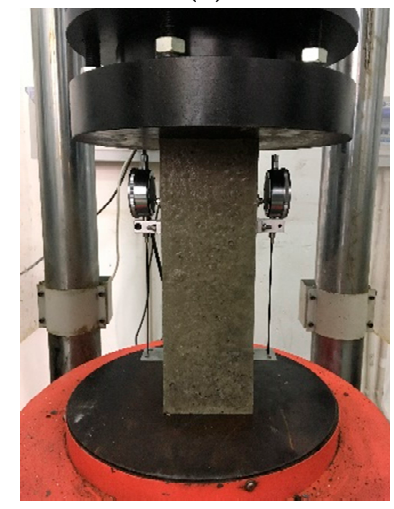

(c)

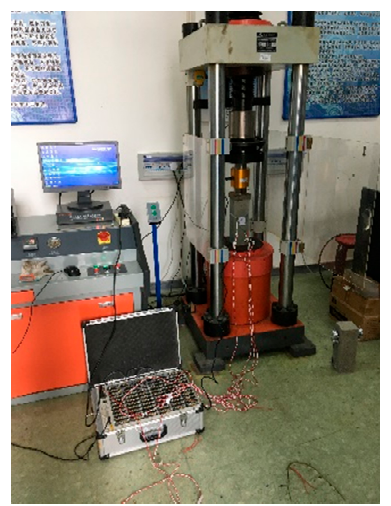

(b)

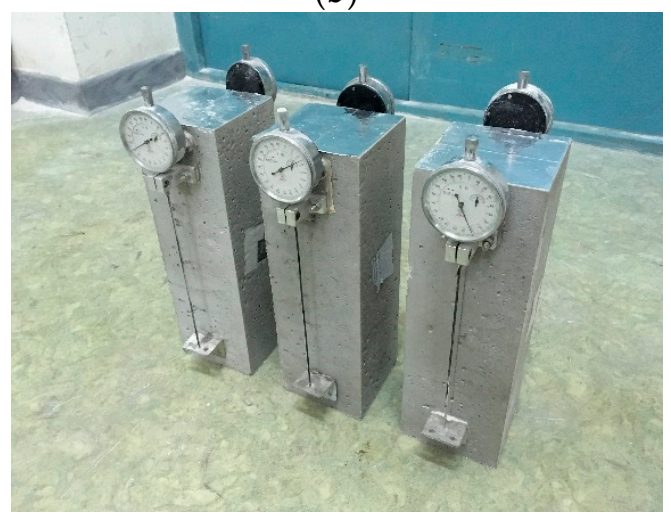

(d)

Figure 2. Tests on compressive strength, elastic modulus and shrinkage: (a) samples used for compressive strength; (b) compressive test; (c) elastic modulus test; (d) shrinkage test.

For the shrinkage test, $100 \times 100 \times 300 \mathrm{~mm}$ prisms of alkali-activated concrete were cast which follows the GB/T 50082-2009 code [23]. When the specimens were demoulded at three days, two dial gauges with a gauge length of $200 \mathrm{~mm}$ were stuck to the opposite sides of the specimens. In order to simulate the water loss state of creep specimens, the top and the bottom of the shrinkage specimens were sealed by aluminum tapes, as Figure $2 \mathrm{~d}$ shown. The shrinkage tests lasted 325 days, and the shrinkage value was determined based on the average value of three specimens.

A self-resisting loading frame was used for the creep test that follows the GB/T 50082-2009 code [23], as shown in Figure 3. The loading frame contains three springs, three pre-stressing rods, a ball joint, four bearing plates (A, B, C, and D), and some bolts for fixation. Bearing plates A and B can be bolted to control the movement. Bearing plate $C$ could move, whereas bearing plate $\mathrm{D}$ was completely fixed.

Ten specimens (in five groups) were cast into $100 \times 100 \times 400 \mathrm{~mm}$ prisms for the creep test. Two dial gauges with a gauge length of $200 \mathrm{~mm}$ were stuck to the opposite sides of each specimen. Each group consisted of the same two specimens, which were stacked one on top of the other. The stacked 
direction of the two specimens ensured that all four sides had a dial gauge to check the bias during the loading, as shown in Figure 3. The stress-strength ratios for the five groups were 0.15, 0.3, 0.45, 0.6 , and 0.75 , respectively. Furthermore, the specimens used in the following tables and figures were named based on their stress-strength ratios.

The creep tests included two stages: a loading stage and a load-keeping stage. During the loading stage, bearing plate A was bolted and bearing plate B was moveable. An oil jack located between bearing plates A and B was used for loading. A pressure sensor was used to monitor the loading and four dial gauges were used to check for eccentricity in both vertical directions. When the eccentricity is over $5 \%$, the jack position and the angle of plate A should be adjusted. The load was slightly higher than experimental value because plate B would experience some deformation after being fixed. When plate B was fixed, it entered the load-keeping stage. The load was checked regularly during this stage. When the stress loss was greater than $5 \%$, more load needed to be added. The deformation is determined based on the mean value of the four dial gauges.

The creep tests lasted 300 days. As for the data equation interval, one day when the test began, then gradually increase to several days in later age. The stress-dependent strain was determined by subtracting the shrinkage strain from the total strain.

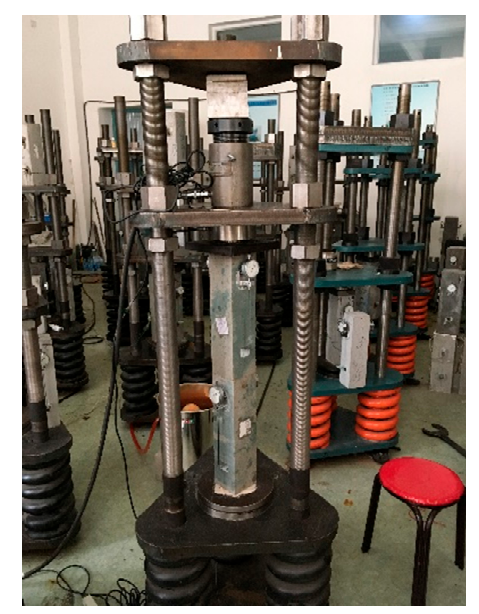

(a)

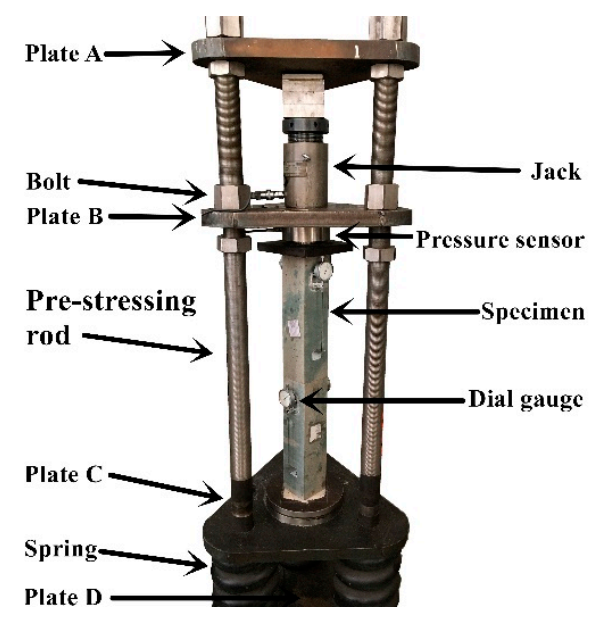

(b)

Figure 3. Self-resisting loading frame. (a) creep laboratory; (b) part name of the frame.

\section{Results and Discussion}

\subsection{Compressive Strength and Elastic Modulus}

The mean compressive strength and elastic modulus of alkali-activated slag concrete samples at 28 days were $43.53 \mathrm{MPa}$ (with standard deviation of 3.57) and 15.3 GPa (with standard deviation of 0.55 ), respectively. The AAS concrete showed a higher compressive strength (in the case of a $w / c$ ratio $=0.5$ ) but a lower elastic modulus than OPC concrete.

Compared with OPC, the hydration product of AAS was C-S-H with a low $\mathrm{H} / \mathrm{S}\left(\mathrm{H}_{2} \mathrm{O} / \mathrm{Si}\right)$ [24], which means the hydration of AAS requires less water. Furthermore, the adsorbed, interlayer, and capillary water in AAS paste [25] was observed, which can support the continuation of hydration. However, we used a w/c ratio of 0.5 to ensure the fluidity for casting. As Figure $1 \mathrm{~b}$ shows, the fresh mixture of AAS remained thick at a high $\mathrm{w} / \mathrm{c}$ ratio. The extra water, which does not activate with the slag, will evaporate as time passes. The loss of water, in turn, causes more microcracks, thus reducing the mechanical strength. We attempted to use a water reducer of Portland cement to reduce the water consumption and improve the strength, which unfortunately did not achieve the desired result. The utilization of a water reducer suitable for AAS is worth further investigation. 
Based on the current models, the elastic modulus of OPC concrete with the same compressive strength is approximately 31.2 to $36.5 \mathrm{GPa}$, as shown in Table 3 .

Table 3. Elastic modulus of model calculation.

\begin{tabular}{ccc}
\hline Model & Compressive Strength (MPa) & Elastic Modulus (GPa) \\
\hline AAS & 43.53 & 15.4 \\
ACI 209R-92 & 43.53 & 36.5 \\
B3 & 43.53 & 31.2 \\
CEB-FIP 2010 & 43.53 & 35.1 \\
GL2000 & 43.53 & 31.9 \\
\hline
\end{tabular}

\subsection{Shrinkage}

The shrinkage test results of AAS concrete is shown in Figure 4. It can be clearly seen that the shrinkage of AAS concrete developed quickly at a young age. At 28 days, the shrinkage reached $163 \mu \varepsilon$. The shrinkage from 3-28 days accounted for over $80 \%$ of the total shrinkage strain. This result also implies that the shrinkage of AAS before day 3 is worth studying. The shrinkage rate of AAS concrete decrease linearly by the dual-logarithmic scale. The main effect of the shrinkage test conducted in this study is deducing the shrinkage strain from the total strain to obtain the stress-dependent strain.

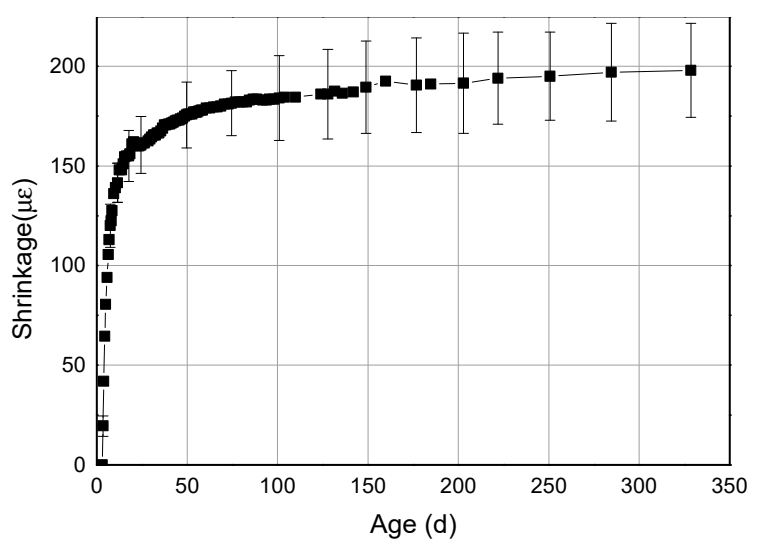

(a)

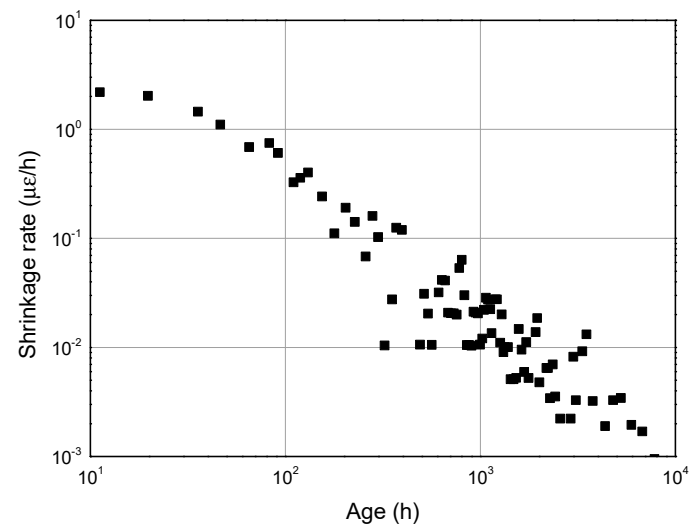

(b)

Figure 4. Shrinkage strain of AAS concrete from day 3. (a) shrinkage strain; (b) shrinkage rate.

\subsection{Creep}

The creep can be divided into three categories from a low to high stress-strength ratio. When the stress level is low, which some authors call service stress, the creep strain is linearly related to the stress. We call this case convergent linear creep, or simply linear creep. As the stress-strength ratio increases, the creep strain is nonlinearly related to the stress, whereas the rate of increase in the creep strain decreases. This case is called convergent nonlinear creep. In this case, although microcracks are generated from the stress, they are not further developed. When the stress-strength ratio increases to a certain extent, the microcracks become more numerous, wider, and joined together. These factors lead to uncontrolled creep growth and eventually to a break of the specimens. This case is called non-convergent creep. The dividing points of linear creep and convergent nonlinear creep of OPC concrete for the current creep models were approximately 0.4 (B3, CEB-FIP 2010, and GL2000) and 0.5 (ACI 209R-92). However, there is no consensus of the dividing point of the convergent nonlinear creep and non-convergent creep of OPC concrete. Some scholars have carried out relevant studies, suggesting a range of $0.7-0.9$ [26-30].

The stress-dependent strain is the sum of the creep strain and elastic strain, the specific creep is the creep strain based on the unit of stress, and the creep coefficient is the ratio of creep strain to the 
elastic strain at the start of the loading time. Samples with a stress-strength ratio of 0.75 broke during the loading time, as shown in Figure 5, and thus are not shown in the data in the following figures. Figure 6 shows the stress-dependent strain, specific creep, and creep coefficient of AAS concrete with different stress-strength ratios for 300 days (beginning at 28 days). Smooth growth curves benefit from good temperature and particularly humidity control.

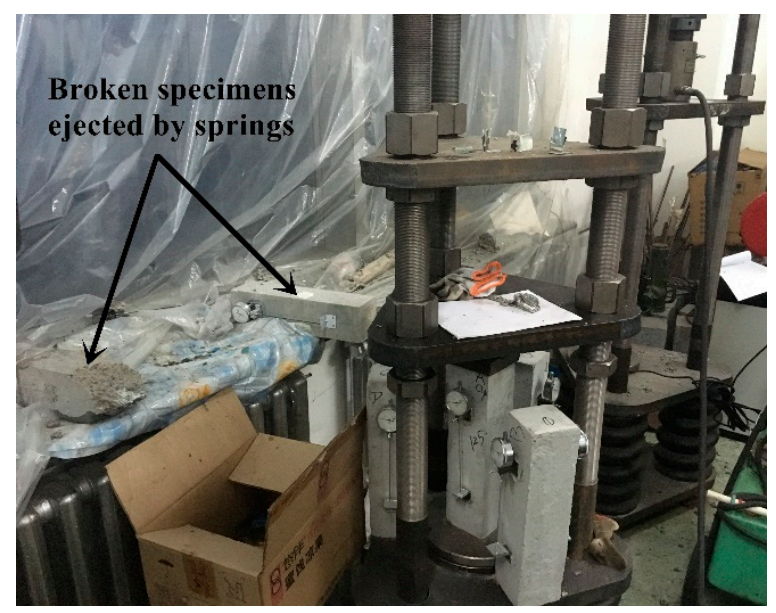

Figure 5. Broken specimens under stress-strength ratio of 0.75 .
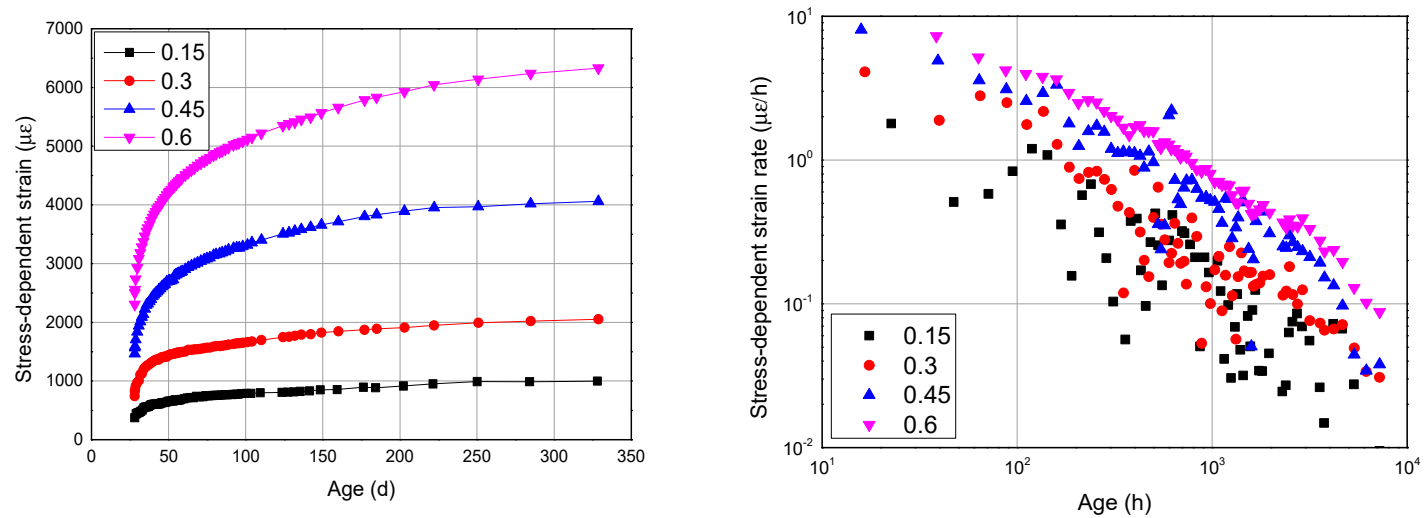

(a)
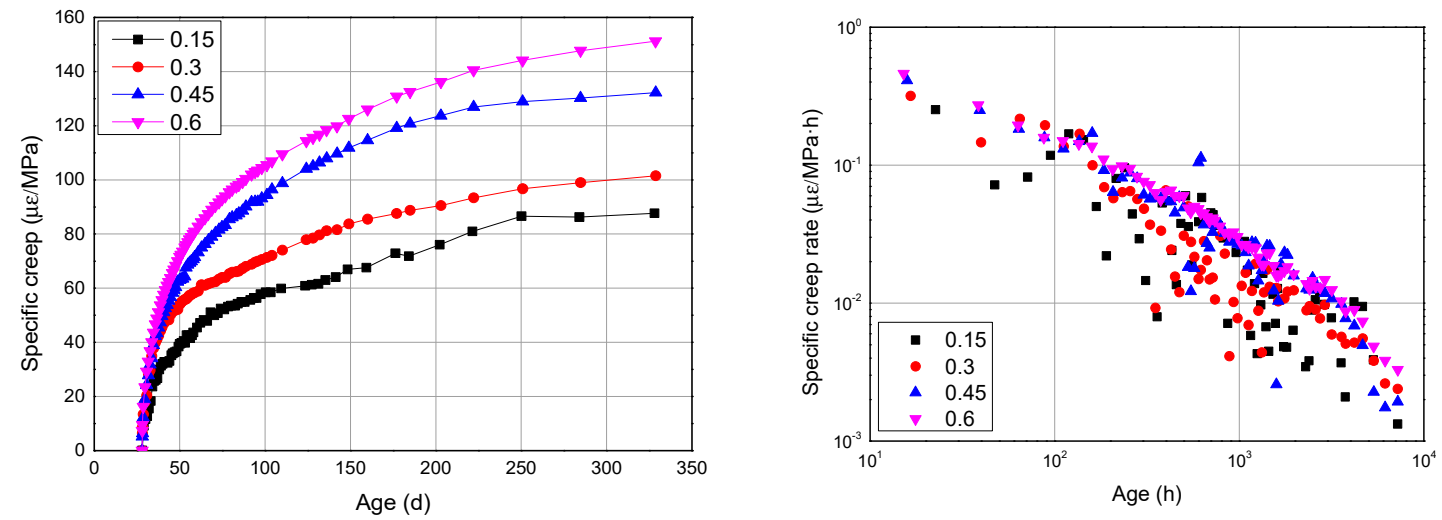

(b)

Figure 6. Cont. 

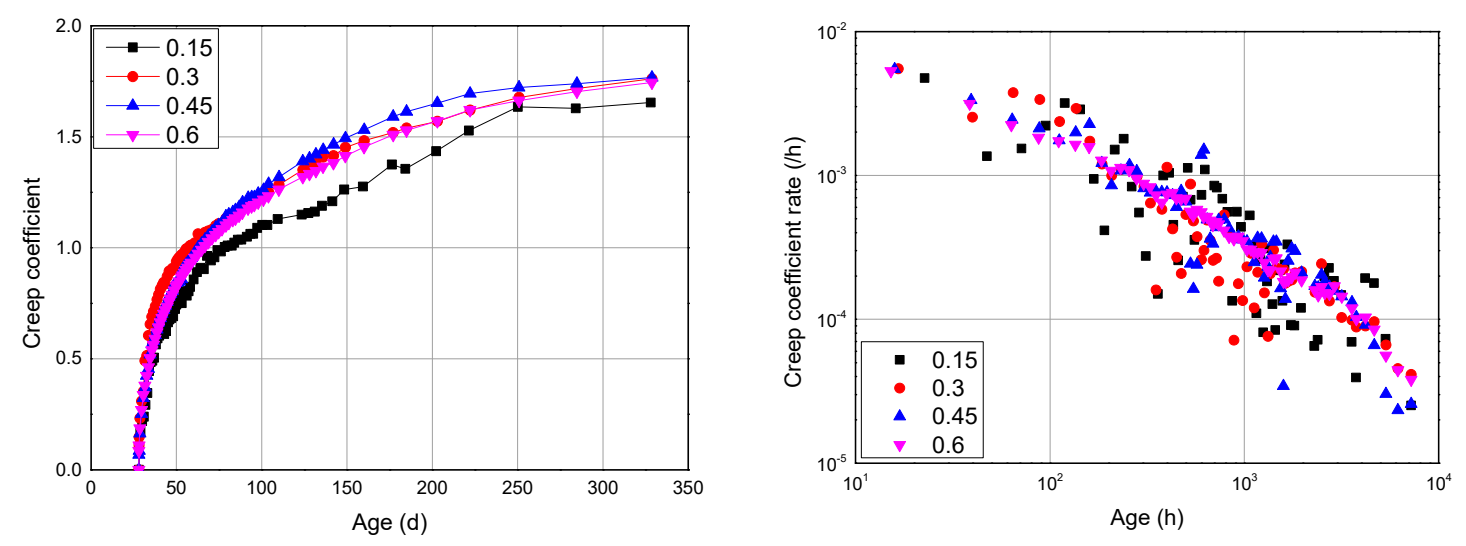

(c)

Figure 6. Effects of stress-strength ratio on the creep property of AAS concrete: (a) stress-dependent strain; (b) specific creep; (c) creep coefficient.

As Figure 6a shows, the stress-dependent strain of all stress-strength ratios increases as the age increases and the rate of growth tapers off. In addition, the stress-dependent strain increases significantly by the growth of the stress-strength ratio. The curves of $0.15-0.6$ show convergence; however, one of the two samples with a stress-strength ratio of 0.75 was broken during the loading time and showed non-convergence. As described in the previous experiment steps, the load was slightly higher than the experimental value because plate B incurred some deformation after being fixed. Thus, the actual stress-strength ratio at the loading time was over 0.75 . While the eccentricity is not the reason of the failure because we were very careful with the eccentricity. The most time-consuming step of loading time is the centering and we usually need more than five times loading process. The results of the stress-dependent strain indicate that the dividing points of convergent nonlinear creep and non-convergent creep of AAS concrete are above 0.6 and approximately 0.75 .

Compared with the stress-dependent strain, the specific creep allowed us to analyze the creep without the effect of stress. As shown in Figure 6b, there are significant distances between the curves. If a linear stage occurs, the specific creep curves of some stress-ratios will be combined. Thus, this result indicates that AAS concrete does not have an obvious range of linear creep, even at a low stress-strength ratio. It seems that the creep of AAS concrete is convergent nonlinear in all ranges of stress-strength ratio if the sample is not experiencing non-convergent creep. This phenomenon is not similar with OPC which has a linear stage (usually under the stress-strength ratio of 0.4 ), a convergent nonlinear stage and a non-convergent stage.

Compared with a specific creep, the creep coefficient allowed us to further analyze the creep without the modulus $\left(\mathrm{GPa}^{-1}\right)$. The creep coefficient is a dimensionless number, which most current models (ACI 209R-92, CEB-FIP 2010, and GL2000) choose to calculate first. As Figure 6c shows, all curves basically overlap together, except for the curve of 0.15 . This may due to the low load applied, which means low accuracy. On the other hand, this may also due to the elastic force of the springs is ideally not borne by the samples. As Figure 3 shows, the removable plate $C$ inevitably experiences friction with pre-stressing rods. When the force is high, the friction is negligible compared to the load. At the same time, a larger creep deformation allows the friction to release faster. When the force is low, the opposite is true, and the friction prevents or delays the creep deformation. All samples with different stress-strength ratios having almost the same creep coefficient is a quite an interesting phenomenon, unlike in OPC concrete. The creep model in CEB-FIP 2010 clearly indicates that when the stress-strength ratio is within the range of 0.4 to 0.6 , the creep coefficient (calculated under a stress-strength ratio of 0.4 ) needs to be multiplied by a factor of greater than 1 [18].

There is another important phenomenon that the rate of three parameters (stress-dependent strain, specific creep, and creep coefficient) decrease near linearly by the dual-logarithmic scale. This 
regularity can make it more convenient for us to understand and predict the long-term creep behavior of AAS concrete. So, in a later paper, we will still attach a rate figure based on dual-logarithmic scale to the edge of each linear scale figure.

Thus, the creep properties of AAS concrete are not similar with those of OPC concrete, e.g., samples with a different stress-strength ratio $(0.15-0.6)$ have almost the same creep coefficient but no obvious range of linear creep.

\section{Code Predictions}

\subsection{Introduction of Current Models}

There are many models of shrinkage and creep for OPC concrete, among which ACI 209R-92, B3, CEB-FIP 2010, and GL2000 have been widely recognized. The ACI 209R-92 model was developed by the American Concrete Institute and is applied in building codes in the US. The B3 model was developed by Bazant and Baweja [20] based on the physical background and a number of parameters. In recent decades, B4 model has been developed based on B3 model. Compared with B3 model, the major innovation of B4 model is the introduction of a split of shrinkage into drying shrinkage and autogenous shrinkage, while this paper is focus on the creep property of the AAS concrete, and we did not measure the autogenous shrinkage. What is more, the B4 model take various admixtures into account while we did not use any admixture in AAS concrete. So, we still use B3 model in this paper. The CEB-FIP 2010 model is contained in the CEB-FIP (2010) Fib Model Code for Concrete Structures, which is applied in Europe. In addition, the GL2000 model was developed by Gardner and Lockman [21]. Compared with other models, fewer parameters are considered in the GL2000 model.

In the ACI 209R-92, CEB-FIP 2010, and GL2000 models, the creep coefficient $\varphi$ is first calculated using different methods. Second, the creep coefficient divided by $E_{28}$ (elastic modulus at 28 days) is used to calculate the specific creep. Third, the specific creep and inverse of Et0 (elastic modulus at loading time) are added to calculate $J$ (creep compliance). Fourth, $J$ is multiplied with the stress to calculate the stress-dependent strain. Finally, the stress-dependent strain is added with the shrinkage strain to calculate the total strain, whereas the B3 model first calculates the parameters $\left(q_{1}, C_{0}\right.$, and $\left.C_{d}\right)$ whose dimensions are consistent with $J\left(\mathrm{GPa}^{-1}\right)$. During these processes, only $q_{1}$ needs to enter the elastic modulus. Then, $J$ is used to calculate $\varphi$.

$$
\begin{gathered}
\varepsilon_{\text {total }}=\varepsilon_{\text {shrinkage }}+\varepsilon_{\text {elastic }}+\varepsilon_{\text {creep }}=\varepsilon_{\text {shrinkage }}+J \sigma \quad \text { All four models } \\
J=\frac{1}{E_{t 0}}+\text { specific creep }=\frac{1}{E_{t 0}}+\frac{\varphi}{E_{28}} \quad \text { ACI 209R-92, CEB-FIP 2010, and GL2000 } \\
J=q_{1}+C_{0}+C_{d} \varphi=E J-1 \quad \text { B3 model }
\end{gathered}
$$

\subsection{Comparison of Shrinkage and Creep of AAS Concrete with Existing Models}

The shrinkage and creep of concrete are influenced by many different factors. Because most models demand a stress-strength ratio of under 0.4 , we chose data with a stress-strength ratio of 0.3 for a comparison of the four models. Table 4 lists the parameters of the four models input to predict the shrinkage and creep. For the parameters that the authors did not measure, let the corresponding value equal 1. It is worth noting that there is no cement type for AAS. Thus, type III was selected, the nature of which is similar to AAS (rapid hardening and high strength) [11,31].

Figure 7 demonstrates the actual drying and model-predicted drying shrinkage of AAS concrete beginning from day 3. It can be clearly seen that, compared with OPC concrete with the same parameters, AAS has a very small amount of drying shrinkage. Nevertheless, this does not mean that AAS concrete has better properties in terms of shrinkage. On the contrary, significant shrinkage and the resulting cracking are problems limiting the application of AAS materials. The AAS materials incur significant autogenous and drying shrinkage, which occurs at an extremely early age [24,32]. 
We also noticed that the shrinkage of AAS tends to become stable earlier at approximately day 30 . This phenomenon illustrates that the hydration of AAS is faster and completed earlier than that of OPC. Because the shrinkage of the AAS is affected by so many different parameters, such as the type of activator, the $\mathrm{SiO}_{2} / \mathrm{Na}_{2} \mathrm{O}$ ratio (in other words, the modulus of sodium silicate) and the activator dosage [31,33], the shrinkage of AAS cannot be studied well using only one mixture proportion. As a result, further improvements to the prediction model are not discussed herein.

Table 4. Parameters input for predicting the shrinkage and creep ("-" indicates that the model does not take this parameter into account).

\begin{tabular}{|c|c|c|c|c|c|}
\hline \multicolumn{2}{|c|}{ Parameters of Models } & \multirow{3}{*}{$\begin{array}{c}\text { ACI 209R-92 } \\
20{ }^{\circ} \mathrm{C} \\
60 \%\end{array}$} & \multirow{3}{*}{$\begin{array}{c}\text { B3 } \\
20{ }^{\circ} \mathrm{C} \\
60 \%\end{array}$} & \multirow{3}{*}{$\begin{array}{c}\text { CEB-FIP } 2010 \\
20{ }^{\circ} \mathrm{C} \\
60 \%\end{array}$} & \multirow{3}{*}{$\begin{array}{c}\text { GL2000 } \\
20^{\circ} \mathrm{C} \\
60 \%\end{array}$} \\
\hline & Temperature & & & & \\
\hline Environment & Relative humidity & & & & \\
\hline \multirow{2}{*}{ Time } & Length and type of curing & 3 days of moistening & 3 days of moistening & 3 days of moistening & 3 days of moistening \\
\hline & Loading age & 28 days & 28 days & 28 days & 28 days \\
\hline \multirow{12}{*}{$\begin{array}{l}\text { Concrete } \\
\text { properties }\end{array}$} & Compressive strength & $43.53 \mathrm{MPa}$ & $43.53 \mathrm{MPa}$ & $43.53 \mathrm{MPa}$ & $43.53 \mathrm{MPa}$ \\
\hline & Size and section shape & $100 \mathrm{~mm}$ cube & $100 \mathrm{~mm}$ cube & $100 \mathrm{~mm}$ cube & $100 \mathrm{~mm}$ cube \\
\hline & Type of cement & III & III & III & III \\
\hline & Slump & $15 \mathrm{~mm}$ & - & - & - \\
\hline & Air content & $1.2 \%$ & - & - & - \\
\hline & Concrete unit weight & $2550 \mathrm{~kg} / \mathrm{m}^{3}$ & - & - & - \\
\hline & Fine aggregate percentage & $33.33 \%$ & - & - & - \\
\hline & Cement content & $333.33 \mathrm{~kg} / \mathrm{m}^{3}$ & - & - & - \\
\hline & Water content & - & $166.67 \mathrm{~kg} / \mathrm{m}^{3}$ & - & - \\
\hline & Water-to-cement ratio & - & 0.5 & - & - \\
\hline & Aggregate-to-cement ratio & - & 6 & - & - \\
\hline & Aggregate type & - & - & Quartzite & - \\
\hline Actual load & & $12.9 \mathrm{MPa}$ & $12.9 \mathrm{MPa}$ & $12.9 \mathrm{MPa}$ & $12.9 \mathrm{MPa}$ \\
\hline
\end{tabular}

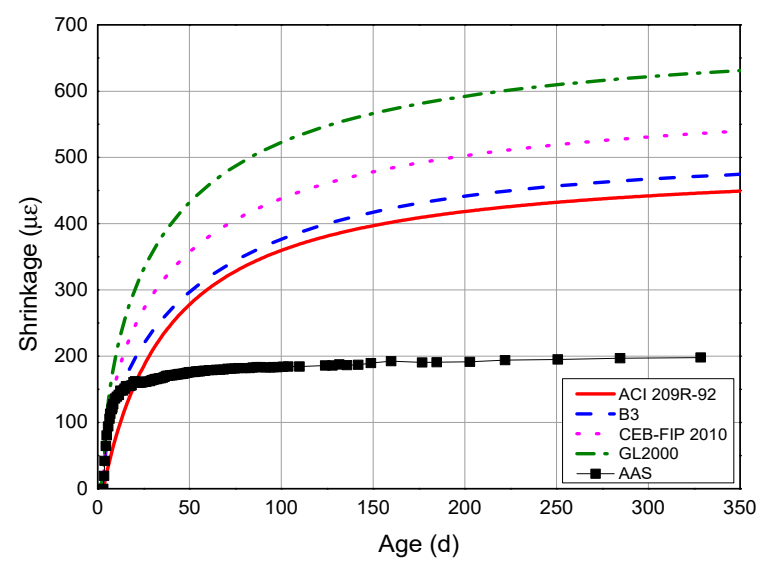

(a)

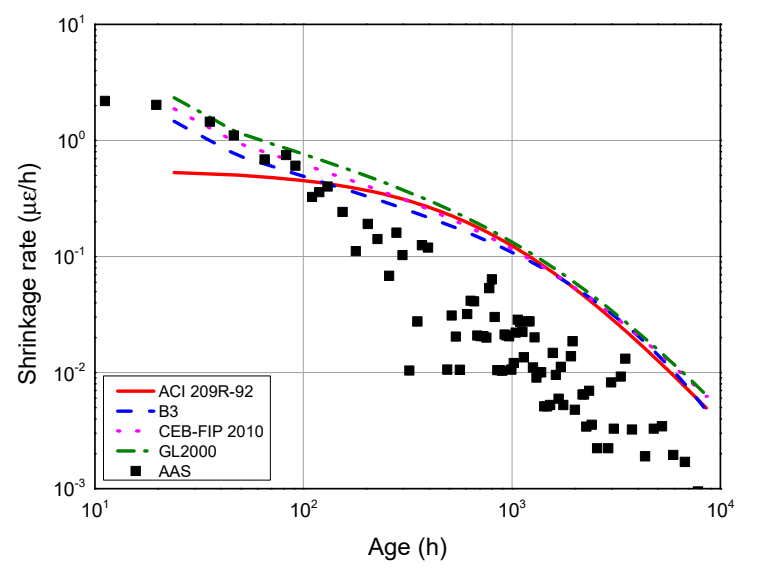

(b)

Figure 7. Drying shrinkage and model-predicted drying shrinkage of AAS concrete beginning from day 3. (a) shrinkage strain; (b) shrinkage rate.

Figure 8 shows a comparison of the stress-dependent strain, specific creep, and creep coefficient between AAS concrete and four different models under the stress-strength ratio of 0.3 for 300 days. The average and standard deviation of residual values by models predicted value minus experimental data value are shown in Table 5, which provide us with the accuracy of the models. It can be clearly seen in Figure 8a that AAS concrete has both a larger elastic strain and creep than OPC concrete under the same parameters. Hence, none of the four models can predict the elastic strain or creep well. Focusing on the elastic strain, the formula used to calculate such strain is $\varepsilon_{\text {elastic }}=\sigma / E_{t 0}$. Thus, the reason for the large elastic strain is the smaller elastic modulus, which can be seen in Table 3.

Next, focusing on the creep, as mentioned before, the specificity allows us to analyze the creep without the effect of stress. In Figure 8b, we can still see that the predicted value of the specific creep is still low. However, when we look at Figure 8c, namely the creep coefficients of the AAS and the 
four models, we can see that the predicted value agrees with the actual value, particularly for the CEB-FIP 2010 and GL2000 models, which have smaller residual values. Compared with the specific creep, the creep coefficient further excludes the effect of the elastic modulus. Herein, we provide a brief summary of why the model prediction of the stress-dependent strain (including the elastic strain and creep) shows a low elastic modulus of AAS concrete.
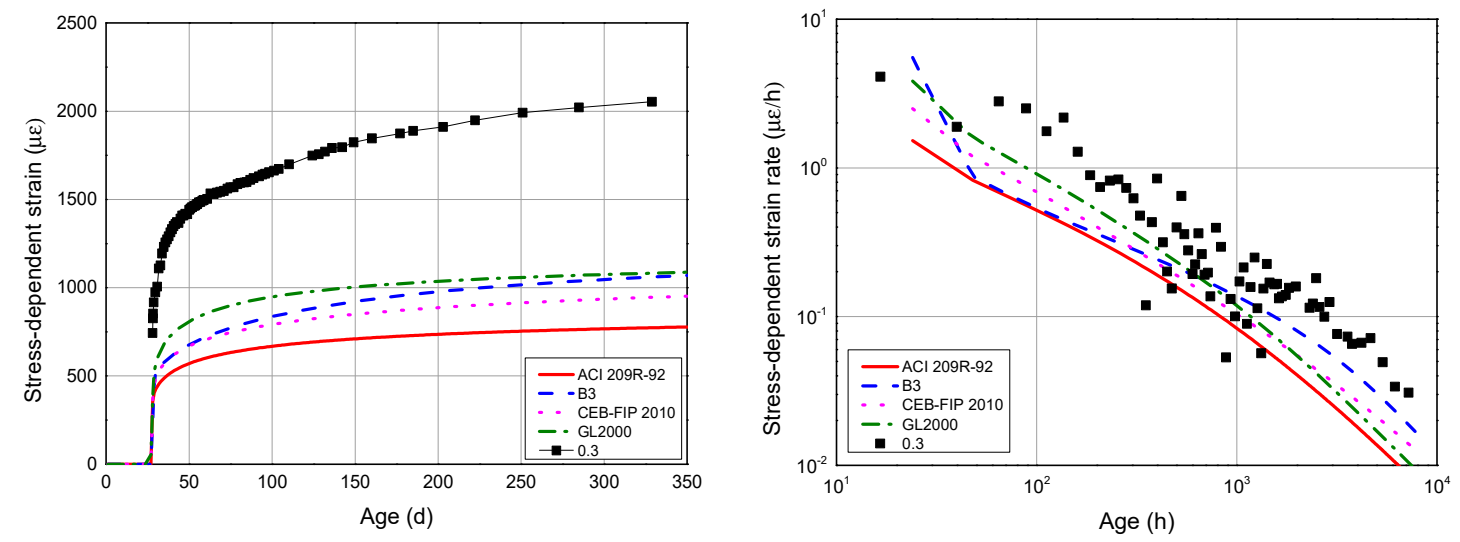

(a)
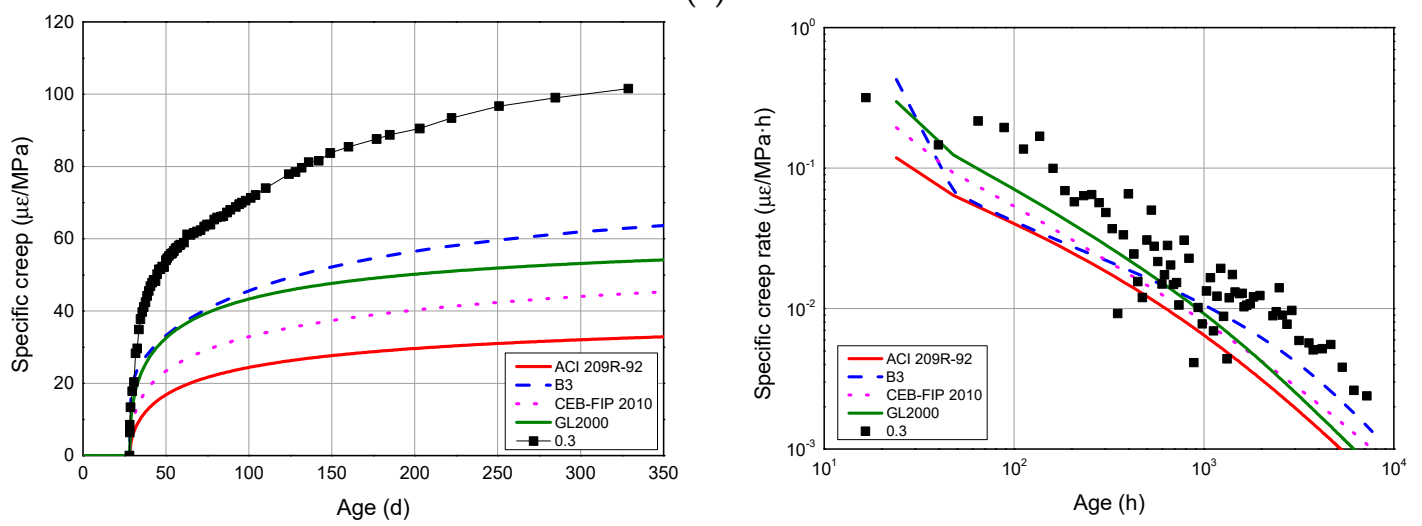

(b)
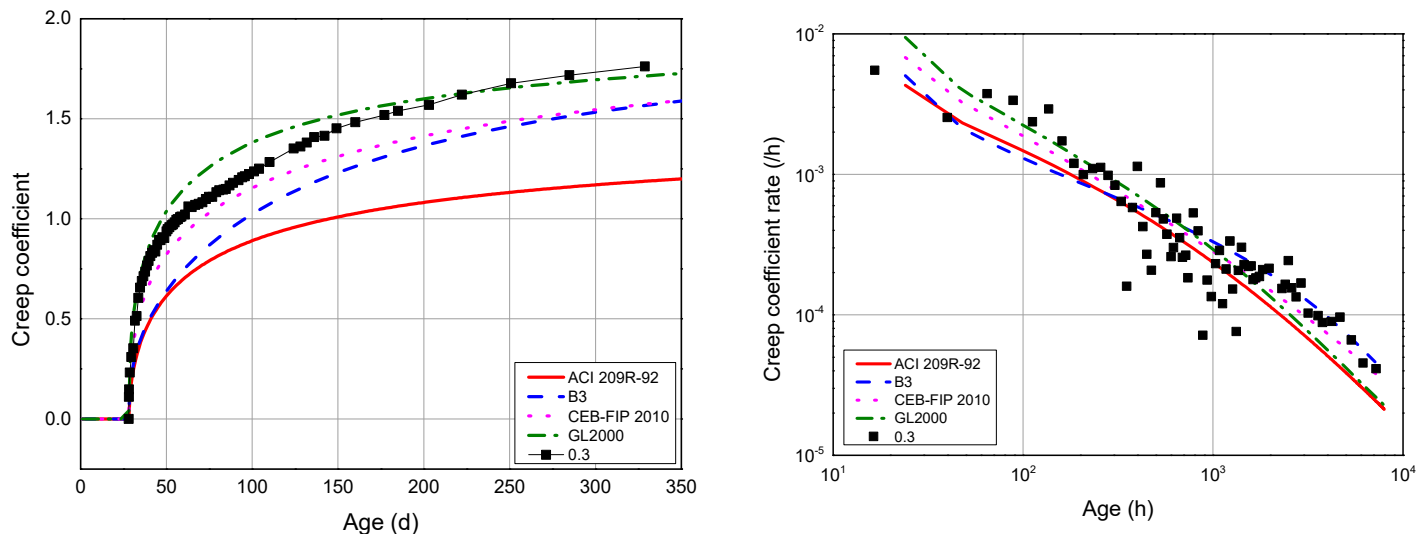

(c)

Figure 8. Comparison of creep in AAS concrete based on the model predictions. (a) stress-dependent strain; (b) specific creep; (c) creep coefficient. 
Table 5. The average and standard deviation of residual values by models predicted value minus experimental data value (shown as average/standard deviation).

\begin{tabular}{cccc}
\hline Model & Stress-Dependent Strain & Specific Creep & Creep Coefficient \\
\hline ACI 209R-92 & $-902 / 183$ & $-39.7 / 14.2$ & $-0.325 / 0.104$ \\
B3 & $-765 / 130$ & $-20.9 / 10.1$ & $-0.233 / 0.067$ \\
CEB-FIP 2010 & $-795 / 153$ & $-32.5 / 11.9$ & $-0.100 / 0.041$ \\
GL2000 & $-660 / 131$ & $-23.6 / 10.1$ & $0.098 / 0.049$ \\
\hline
\end{tabular}

\subsection{Comparison of Creep of AAS Concrete Using the Adjustment Models}

As described in the previous section, the OPC concrete creep model can predict the creep coefficient well. The elastic modulus of AAS concrete is needed to predict the creep further. Although the elastic modulus tested by the standard method (at a stress-strength ratio of 0.33 ) is shown in Table 3, it is not used directly herein because, when we compare Figure $6 b, c$, the creep of AAS concrete under different stress-strength ratios has almost the same creep coefficient but a different specific creep. If we use the same creep coefficient divided by a unified elastic modulus to calculate the specific creep, we will not obtain a disparate specific creep under a stress-strength ratio of 0.4 . Thus, we need to use the secant modulus of AAS concrete under different stress-strength ratios. For this reason, we use the actual stress (determined through the pressure sensor on the creep frame) and strain (mean value of the four dial gauges on the specimens) to calculate the secant modulus. The results are shown in Table 6 and Figure 9a. We also apply the results (adding the elastic modulus under a stress-strength ratio of 0.33 ) in Table 3 and conduct a linear fitting, as shown in Figure 9b, for further prediction.

Table 6. The secant modulus under different stress-strength ratios.

\begin{tabular}{cccccc}
\hline Sample Name & $\mathbf{0 . 1 5}$ & $\mathbf{0 . 3}$ & Elastic Modulus Test & $\mathbf{0 . 4 5}$ & $\mathbf{0 . 6}$ \\
\hline Target stress-strength ratio & 0.15 & 0.30 & 0.33 & 0.45 & 0.60 \\
Actual stress $(\mathrm{MPa})$ & 7.1 & 12.9 & 14.4 & 19.6 & 26.6 \\
Actual strain $(\mu \varepsilon)$ & 376 & 744 & 940 & 1468 & 2306 \\
Actual stress-strength ratio & 0.16 & 0.30 & 0.33 & 0.45 & 0.61 \\
Secant modulus $(\mathrm{GPa})$ & 18.9 & 17.3 & 15.3 & 13.4 & 11.5 \\
\hline
\end{tabular}

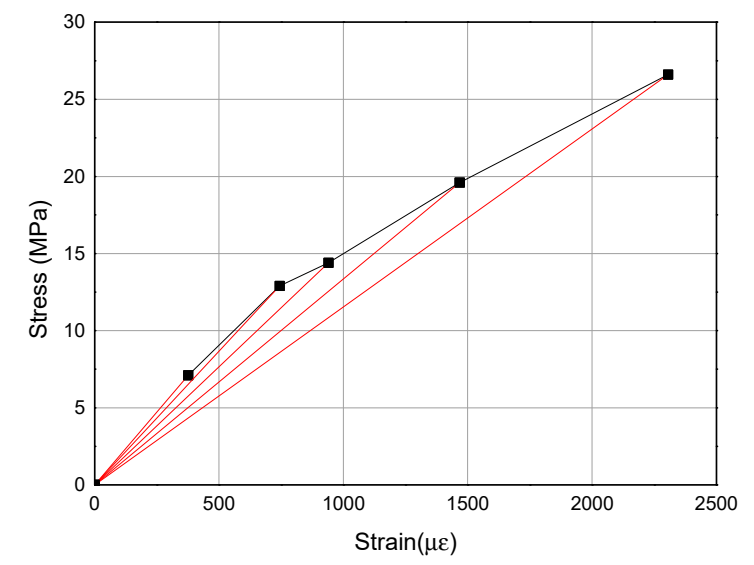

(a)

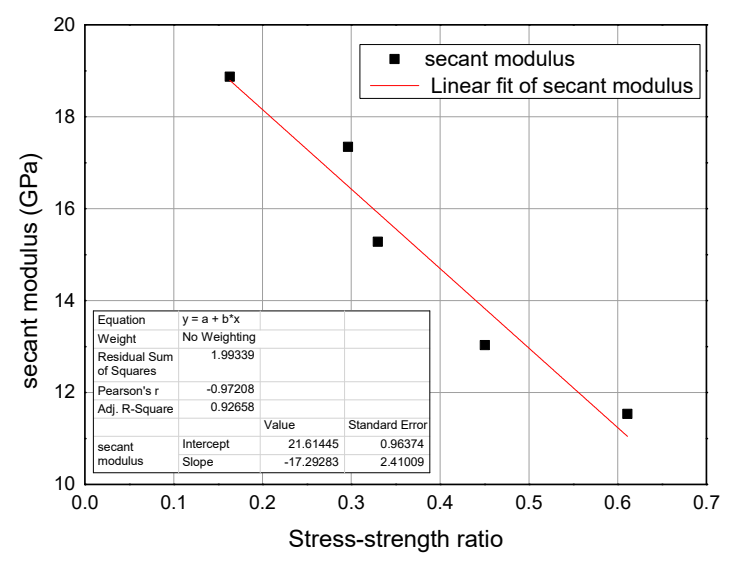

(b)

Figure 9. Secant modulus of AAS under different stress-strength ratios and their linear fit. (a) stressstrain relation; (b) linear fit of scant modulus under different stress-strength ratio.

Next, we chose a stress-strength of 0.3 , the actual elastic modulus of 17.3 GPa was used in the re-prediction by the four models, the results of which are listed in Figure 10. The average and standard deviation of residual values by adjustment models predicted value minus experimental data value are shown in Table 7. 
As mentioned before, the ACI 209R-92, CEB-FIP 2010, and GL2000 models calculate the creep coefficient $\varphi$ first. Thus, when the input elastic modulus decreases, the creep coefficients are not changed, and the specific creep and stress-dependent strain increase. Moreover, the prediction of these three models improve after change in the elastic modulus. Compare with the Tables 5 and 7 , the average residual values of stress-dependent strain prediction by ACI 209R-92, CEB-FIP 2010, and GL2000 reduce 73\%, 91\%, and 88\%, respectively. The average residual values of specific creep prediction by ACI 209R-92, CEB-FIP 2010, and GL2000 reduce 53\%, 82\%, and 76\%, respectively.
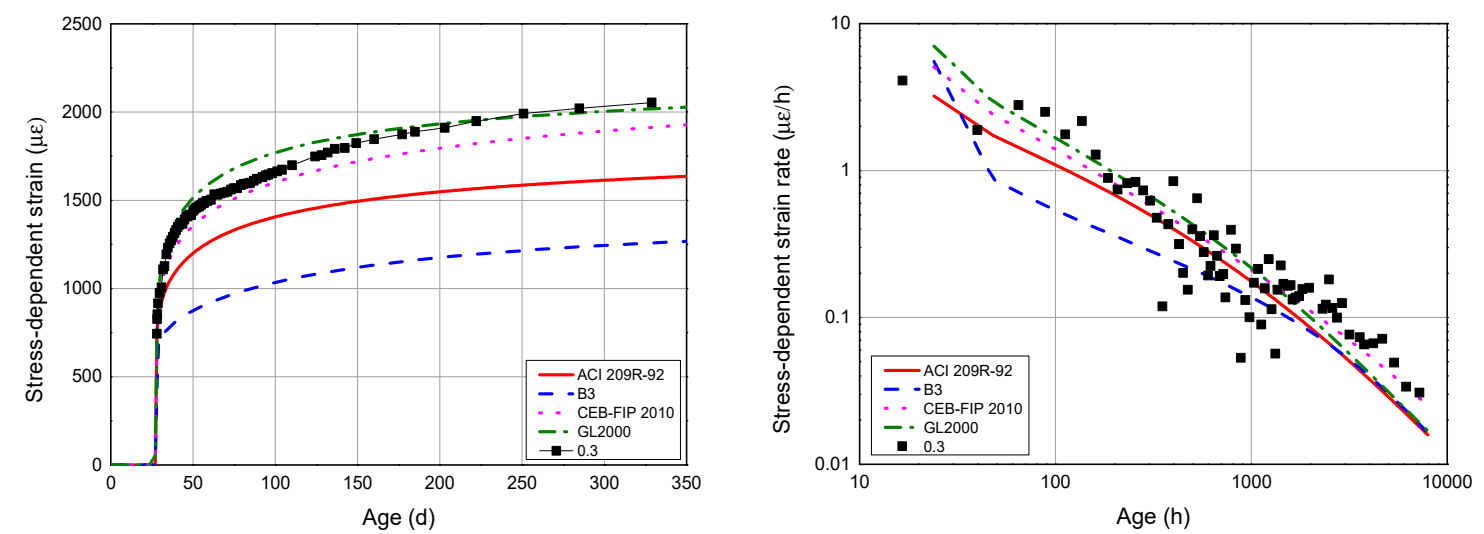

(a)
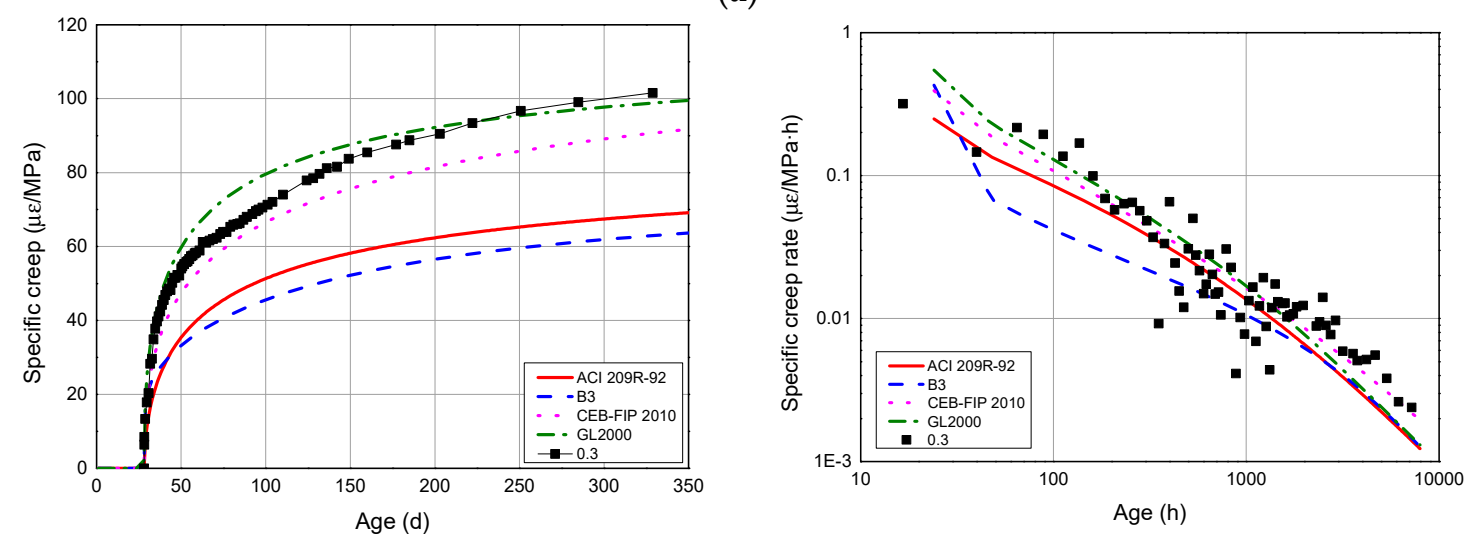

(b)
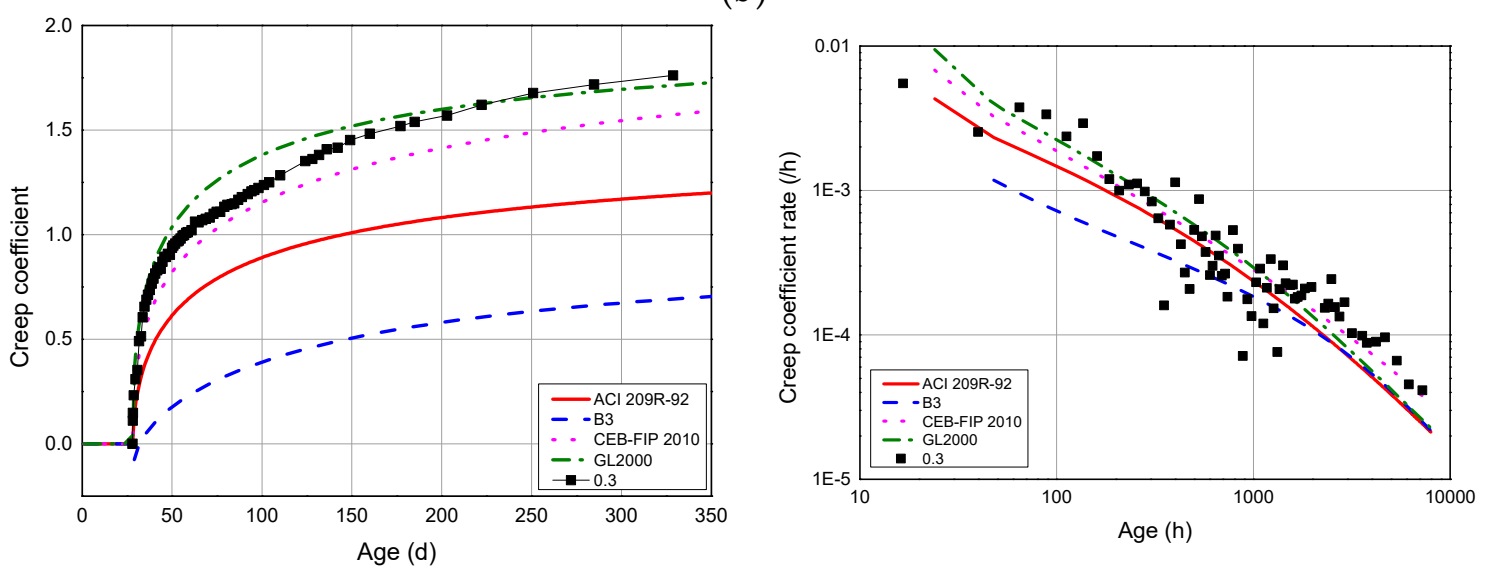

(c)

Figure 10. Comparison of creep in AAS concrete using adjustment models. (a) stress-dependent strain; (b) specific creep; (c) creep coefficient. 
Table 7. The average and standard deviation of residual values by adjustment models predicted value minus experimental data value (shown as average/standard deviation).

\begin{tabular}{cccc}
\hline Model & Stress-Dependent Strain & Specific Creep & Creep Coefficient \\
\hline ACI 209R-92 & $-242 / 77$ & $-18.8 / 6.0$ & $-0.325 / 0.104$ \\
B3 & $-567 / 130$ & $-20.9 / 10.1$ & $-0.757 / 0.193$ \\
CEB-FIP 2010 & $-74 / 30$ & $-5.7 / 2.3$ & $-0.100 / 0.041$ \\
GL2000 & $76 / 36$ & $5.6 / 2.8$ & $0.098 / 0.049$ \\
\hline
\end{tabular}

However, the B3 model calculates the parameters belonging to the specific creep $\left(\mathrm{GPa}^{-1}\right)$. During the calculation of these parameters $\left(C_{0}\right.$ and $\left.C_{d}\right)$, there is no elastic modulus input. Thus, the variation of the elastic modulus does not change the specific creep, which can be been seen from Figures $8 \mathrm{~b}$ and $10 \mathrm{~b}$. As these figures indicate, we can see that the decrease in elastic modulus only allows an increase in the elastic stain $\left(q_{1}\right)$. Worse still, the prediction of the creep coefficient calculated by the specific creep becomes poor and even generates a negative value owing to the direct change in the elastic modulus. Thus, the B3 model is suitable for calculating the creep of OPC concrete but not that of AAS concrete.

\subsection{Improved Creep Model for AAS Concrete with a Wide Range of Stress-Strength Ratios}

In the previous section, we use adjustment models to predict the creep of AAS concrete. When the four models predict the creep of OPC concrete, the use of more parameters typically means better accuracy. However, more parameters mean the model is more firmly bound to the OPC concrete. Thus, a model with fewer parameters may be more suitable for predicting the creep in new materials. So, the CEB-FIP 2010 and GL2000 creep models with fewer parameters show the better accuracy for predicting the creep of AAS concrete.

The CEB-FIP 2010 model has similar prediction accuracy with GL2000 model and superiority in the early time prediction. However, there are more data points in early time than the later time, which means the GL2000 has more superiority in accuracy and long time prediction. Furthermore, the residual values of the GL2000 model are positive value which means the predicted value is higher than the actual data values. It is safer from the perspective of practical engineering application.

For several reasons above, we propose an improved creep model for AAS concrete with a wide range of stress-strength ratios based on the GL2000 model with an improved formula of the secant modulus used to replace the elastic modulus.

The calculation of the secant modulus is based on Figure 9.

$$
E_{\text {secant }}=E_{\text {elastic }}-(-1)^{\sigma-\sigma_{E}} \times\left(\frac{17.3 \sigma}{f_{c m 28}}\right)
$$

where $E_{\text {secant }}$ is the secant modulus, $E_{\text {elastic }}$ is the elastic modulus determined through the testing, $\sigma$ is the actual stress corresponding to the sample, $\sigma_{E}$ is the stress of the elastic modulus test, and $f_{\mathrm{cm} 28}$ is the compressive strength of the concrete. The $\sigma-\sigma_{E}$ is used for control the symbol of -1 which mean when the stress-strength ratio is higher than the stress-strength ratio of the elastic modulus test, the secant modulus would lower than the elastic modulus. When the stress-strength ratio is lower than the stress-strength ratio of the elastic modulus test, the reverse is also true. The $\sigma / f_{c m} 28$ means the stress-strength ratio, which is also the independent variable in Figure 9. The 17.3 is the slope based on the linear fit result of the Figure 9.

We then use $E_{\text {secant }}$ to replace the elastic modulus to calculate the specific creep and stress-dependent strain. The prediction of stress-dependent strain and the specific creep of AAS concrete under a wide range of stress-strength ratios using the improved creep model (curves containing " $\mathrm{M}$ " in their name), as well as the test results, are shown in Figure 11. The average and standard deviation of residual values by improved model are shown in Table 8 . The prediction of the stress-dependent strain is fairly accurate, whereas the prediction of the specific creep under a stress-strength ratio of 0.45 is insufficient. 
Table 8. The average and standard deviation of residual values by improved model predicted value minus experimental data value (shown as average/standard deviation).

\begin{tabular}{cccc}
\hline Stress-Strength Ratio & Stress-Dependent Strain & Specific Creep & Creep Coefficient \\
\hline M-0.15 & $101 / 26$ & $14.1 / 3.7$ & $0.263 / 0.070$ \\
M-0.3 & $150 / 40$ & $8.8 / 3.1$ & $0.098 / 0.049$ \\
M-0.45 & $72 / 130$ & $6.6 / 6.7$ & $0.132 / 0.018$ \\
M-0.6 & $540 / 151$ & $17.3 / 5.7$ & $0.162 / 0.067$ \\
\hline
\end{tabular}
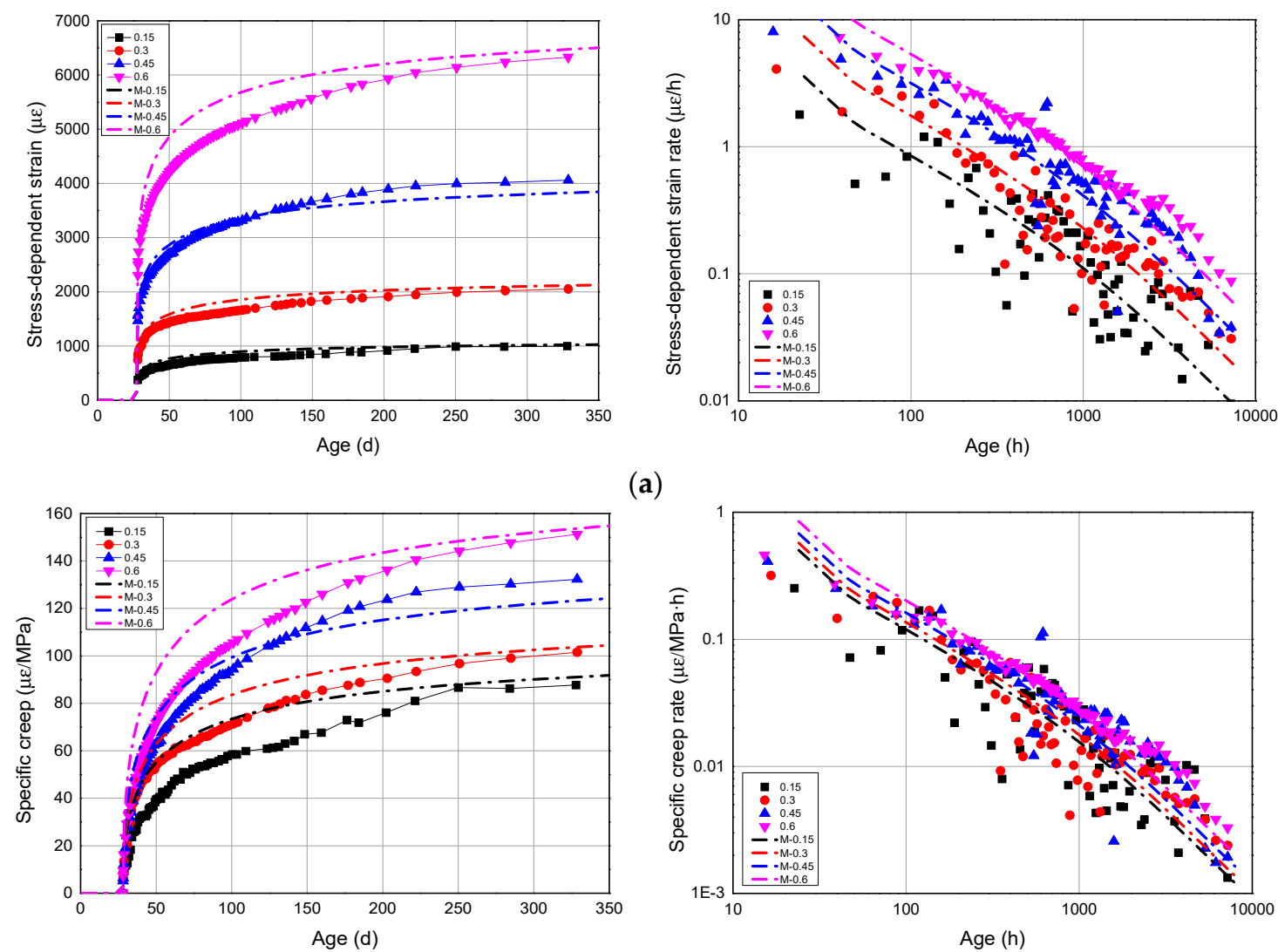

(a)

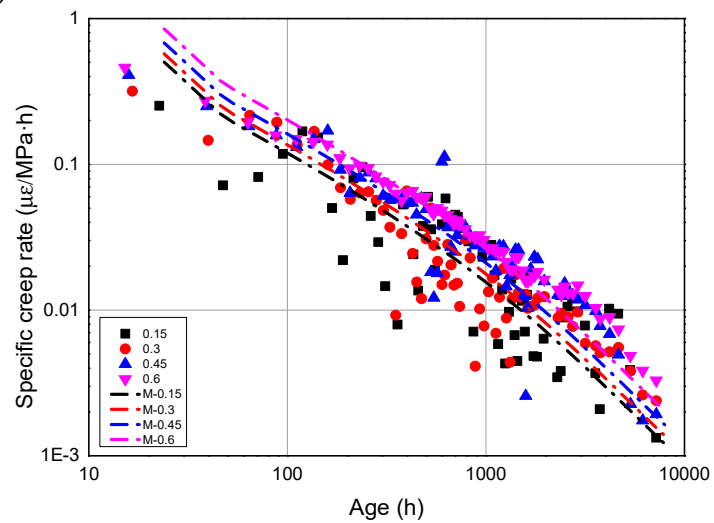

(b)
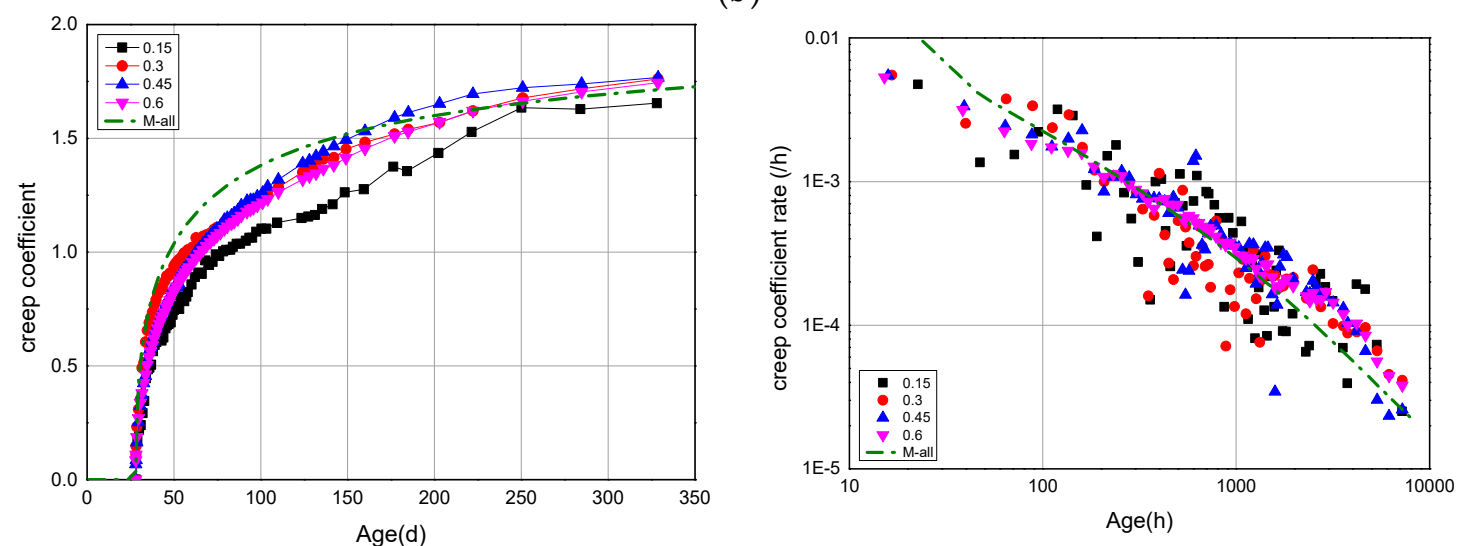

(c)

Figure 11. Test values compared with improved creep model. (a) stress-dependent strain; (b) specific creep; (c) creep coefficient. 


\section{Conclusions}

In this study, the mechanical and time-dependent properties, particularly the creep of AAS concrete with five different stress-strength ratios $(0.15,0.3,0.45,0.6$, and 0.75$)$, were studied. After comparing the creep of AAS concrete using the current models (ACI 209R-92, B3, CEB-FIP 2010, and GL2000), we analyzed the cause of the deviation and proposed an improved creep model for AAS concrete with a wide range of stress-strength ratios based on the GL2000 model. The main conclusions drawn are as follows:

(1) The AAS concrete shows greater compressive strength (for $w / c$ ratio $=0.5$ ) but a lower elastic modulus than OPC concrete.

(2) At a stress-strength ratio of $0.15-0.75$, the creep of AAS concrete has a convergent nonlinear stage and a non-convergent stage but not an obvious linear stage. This phenomenon differs from OPC concrete, which has a linear creep stage and is typically under a stress-strength ratio of 0.4 . The dividing points of the convergent nonlinear creep and non-convergent creep of AAS concrete are above 0.6 and approximately 0.75 , which are quite similar with those of OPC concrete.

(3) AAS concrete basically has a consistent creep coefficient under a stress-strength ratio of $0.15-0.6$ and provides a convenient way to achieve a creep prediction. This property differs with OPC concrete, which has different creep coefficients between the service stress (usually under 0.4 ) and high stress-strength ratio (usually above 0.4 ).

(4) The rate of three parameters (stress-dependent strain, specific creep, and creep coefficient) of AAS concrete decrease near linearly by the dual-logarithmic scale. This regularity can make it more convenient for us to understand and predict the long-term creep behavior of AAS concrete.

(5) The four creep models are good at predicting the creep coefficient, but not the specific creep and stress-dependent strain of AAS concrete. AAS concrete exhibits greater elastic strain and creep than OPC concrete under the same parameters. As the reason for this, the elastic modulus of AAS concrete with the same strength as OPC concrete is not similar to the elastic modulus calculated by the models.

(6) By applying the actual elastic modulus, except for the B3 model, the models can predict the specific creep and stress-dependent strain of AAS concrete with a stress-strength ratio of 0.3 or better. This is due to the B3 model calculating the parameters belonging to the specific creep, and during this period, without directly inputting the elastic modulus.

(7) The secant modulus of AAS concrete is sensitive to the stress-strength ratio. The secant modulus decreases linearly with an increase in the stress-strength ratio. We thus proposed a formula to calculate the secant modulus of AAS concrete.

(8) Based on the GL2000 model and using the secant modulus to replace the elastic modulus, we proposed an improved creep model for AAS concrete with a wide range of stress-strength ratios.

Author Contributions: Investigation, X.Z.; resources, W.Z.; data curation, X.Z. and Y.Z.; writing-original draft preparation, X.Z.; writing-review and editing, X.Z and P.C.; supervision, W.Z.; project administration, W.Y.; funding acquisition, W.Y.

Funding: This research was funded by the National Natural Science Foundation of China, grant number 51478142.

Conflicts of Interest: The authors declare no conflict of interest.

\section{References}

1. Jiao, Z.; Wang, Y.; Zheng, W.; Huang, W. Effect of dosage of sodium carbonate on the strength and drying shrinkage of sodium hydroxide based alkali-activated slag paste. Constr. Build. Mater. 2018, 179, 11-24. [CrossRef]

2. Rashad, A.M.; Zeedan, S.R. The effect of activator concentration on the residual strength of alkali-activated fly ash pastes subjected to thermal load. Constr. Build. Mater. 2011, 25, 3098-3107. [CrossRef] 
3. Sinton, J. Energy efficiency for greenhouse gas emission reduction in China: The case of the cement industry. Br. J. Dermatol. 1996, 170, 1177-1181.

4. Provis, J.L.; Brice, D.G.; Buchwald, A.; Duxson, P.; Kavalerova, E.; Krivenko, P.V.; Shi, C.; Deventer, J.S.J.V.; Wiercx, J.A.L.M. Demonstration Projects and Applications in Building and Civil Infrastructure. In Alkali Activated Materials; Springer: Dordrecht, The Netherlands, 2014.

5. Provis, J.L. Alkali-activated materials. Cem. Concr. Res. 2018, 114, 40-48. [CrossRef]

6. Bakharev, T.; Sanjayan, J.G.; Cheng, Y.B. Resistance of alkali-activated slag concrete to acid attack. Cem. Concr. Res. 2003, 33, 1607-1611. [CrossRef]

7. Komljenović, M.; Baščarević, Z.; Marjanović, N.; Nikolić, V. External sulfate attack on alkali-activated slag. Constr. Build. Mater. 2013, 49,31-39. [CrossRef]

8. Kim, J.; Moon, J.H.; Shim, J.W.; Sim, J.; Lee, H.G.; Zi, G. Durability properties of a concrete with waste glass sludge exposed to freeze-and-thaw condition and de-icing salt. Constr. Build. Mater. 2014, 66, 398-402. [CrossRef]

9. Cai, L.; Wang, H.; Fu, Y. Freeze-thaw resistance of alkali-slag concrete based on response surface methodology. Constr. Build. Mater. 2013, 49, 70-76. [CrossRef]

10. Fernández-Jiménez, A.; Palomo, J.G.; Puertas, F. Alkali-activated slag mortars: Mechanical strength behaviour. Cem. Concr. Res. 1999, 29, 1313-1321. [CrossRef]

11. Gebregziabiher, B.S.; Thomas, R.J.; Peethamparan, S. Temperature and activator effect on early-age reaction kinetics of alkali-activated slag binders. Constr. Build. Mater. 2016, 113, 783-793. [CrossRef]

12. Yazdizadeh, Z.; Marzouk, H.; Hadianfard, M.A. Monitoring of concrete shrinkage and creep using Fiber Bragg Grating sensors. Constr. Build. Mater. 2017, 137, 505-512. [CrossRef]

13. Collins, F.G.; Sanjayan, J.G. Workability and mechanical properties of alkali activated slag concrete. Cem. Concr. Res. 1999, 29, 455-458. [CrossRef]

14. Pang, C.; Zheng, W.; Ying, W.; Wei, C. Analysis and Modelling of Shrinkage and Creep of Reactive Powder Concrete. Appl. Sci. 2018, 8, 732 .

15. Domingo-Cabo, A.; Lázaro, C.; López-Gayarre, F.; Serrano-López, M.A.; Serna, P.; Castaño-Tabares, J.O. Creep and shrinkage of recycled aggregate concrete. Constr. Build. Mater. 2009, 23, 2545-2553. [CrossRef]

16. Seara-Paz, S.; González-Fonteboa, B.; Martínez-Abella, F.; González-Taboada, I. Time-dependent behaviour of structural concrete made with recycled coarse aggregates. Creep and shrinkage. Constr. Build. Mater. 2016, 122, 95-109. [CrossRef]

17. Ma, J.; Dehn, F.; Ma, J.; Dehn, F.; Ma, J.; Dehn, F.; Ma, J.; Dehn, F.; Ma, J.; Dehn, F. Shrinkage and creep behavior of an alkali-activated slag concrete. Struct. Concr. 2017, 18, 801-810. [CrossRef]

18. Betonbau. Fib Model Code for Concrete Structures 2010; Ernst \& Sohn: Hoboken, NJ, USA, 2013.

19. ACI Committee 209. Guide for Modeling and Calculating Shrinkage and Creep in Hardened Concrete; American Concrete Institute: Farmington Hills, MI, USA, 1992.

20. Bazant, Z.P.; Baweja, S. Creep and shrinkage prediction model for analysis and design of concrete structures-Model B 3. Mater. Struct. 1995, 28, 357-365.

21. Gardner, N.J.; Lockman, M.J. Design Provisions for Drying Shrinkage and Creep of Normal Strength Concrete. ACI Mater. J. 2001, 98, 159-167.

22. GB/T 50081-2002. Standard for Test Method of Mechanical Properties on Ordinary Concrete; Chinese Architecture and Building Press: Beijing, China, 2002.

23. GB/T 50082-2009. Standard for Test Methods of Long-Term Performance and Durability of Ordinary Concrete; Chinese Architecture and Building Press: Beijing, China, 2009.

24. Thomas, J.J.; Allen, A.J.; Jennings, H.M. Density and water content of nanoscale solid C-S-H formed in alkali-activated slag (AAS) paste and implications for chemical shrinkage. Cem. Concr. Res. 2012, 42, 377-383. [CrossRef]

25. Ye, H.; Radlińska, A. Shrinkage mechanisms of alkali-activated slag. Cem. Concr. Res. 2016, 88, $126-135$. [CrossRef]

26. Beres, L. Fracture of concrete subjected to cyclic and sustained loading. ACI J. Proc. 1970, 67, 816-827.

27. Rusch, H. Researches toward a General Flexural Theory for Structural Concrete. Am. Concr. Inst. J. Proc. 1960, 57, 1-28.

28. Smadi, M.M.; Slate, F.O.; Nilson, A.H. Shrinkage and Creep of High-, Medium-, and Low-Strength Concretes, Including Overloads. ACI Mater. J. 1987, 84, 224-234. 
29. Claeson, C.; Gylltoft, K. Slender concrete columns subjected to sustained and short-term eccentric loading. ACI Struct. J. 2000, 97, 45-52.

30. Iravani, S.; Macgregor, J.G. Sustained Load Strength and Short-Term Strain Behavior of High-Strength Concrete. ACI Mater. J. 1998, 95, 636-647.

31. Aydin, S.; Baradan, B. Effect of activator type and content on properties of alkali-activated slag mortars. Compos. Part B 2014, 57, 166-172. [CrossRef]

32. Neto, A.A.M.; Cincotto, M.A.; Repette, W. Drying and autogenous shrinkage of pastes and mortars with activated slag cement. Cem. Concr. Res. 2008, 38, 565-574. [CrossRef]

33. Krizan, D.; Zivanovic, B. Effects of dosage and modulus of water glass on early hydration of alkali-slag cements. Cem. Concr. Res. 2002, 32, 1181-1188. [CrossRef]

(C) 2019 by the authors. Licensee MDPI, Basel, Switzerland. This article is an open access article distributed under the terms and conditions of the Creative Commons Attribution (CC BY) license (http://creativecommons.org/licenses/by/4.0/). 